\title{
Hacia la globalización del tópico andaluz: Andalucía te quiere
}

\author{
Cinta Ma Cano Figueroa I cinta.cano.fig@gmail.com
}

UnIVERSIDAD DE SEVILLA

Resumen: El análisis de la campaña Andalucía te quiere supone una revisión del uso dado a rasgos semánticos recurrentes que identifican a esta comunidad autónoma con valores asumidos socialmente. En la publicidad turística se evidencia el desarrollo de una argumentación apoyada en dichas concepciones culturales comunes y complementadas emotivamente gracias a la aplicación del Marketing Experiencial. Igualmente se pretende resaltar que gracias a la amplia proliferación de redes sociales y a la cada vez más previsible importancia dada a los medios digitales, campañas como ésta buscan difusión de cara al gran escaparate que supone la red Internet.

Palabras clave: tópicos, publicidad turística, isotopías, contextos digitales, publicidad experiencial.

Abstract: The analysis of Andalucía te quiere campaign is a review of the use given to recurring semantic features that identify this region with socially accepted values. In the touristic advertising an argument is developing supported by these common cultural conceptions and emotionally complemented through the application of experiential marketing. It is also proposed to highlight that thanks to the extensive proliferation of social networks and to the increasingly predictable importance of digital media, campaigns like this seek to broadcast in the great showcase that involves Internet.

Key words: topics, touristic advertising, isotopies, digital contexts, experiential marketing. 


\section{Introducción}

Con el inicio del boom turístico en España en los años sesenta, el sector publicitario tuvo que esforzarse en encontrar reclamos que atrajeran a más turistas hacia nuestro país. Es cierto que, en la misma época, España trataba de modernizarse social y económicamente, pero se encontraba aún bajo la atenta mirada del régimen dictatorial de Franco. El interés por ciertos destinos turísticos cobra importancia debido a una nueva forma de argumentar, que hace gran uso de determinados valores generalmente aceptados: los tópicos.

En el caso de la publicidad turística española se aprecia el uso de valores como naturaleza, clima, fiesta o pasión; valores que son extrapolables a la comunidad autónoma andaluza, región en la que se enmarca el presente estudio. En su mayoría, la publicidad turística se decanta por usar un marcado tono sensual, precisamente buscando cierta atracción en el consumidor final. Dicha sensualidad suele venir ligada a estrategias comunicativas y, en el caso andaluz, a aspectos como el clima, la cultura, el folclore o la gastronomía, al ser éstos reconocidos como lugares comunes o claves fundamentales para la posterior lectura de estos mensajes publicitarios.

Con este estudio se pretende revisar el uso que se le está dando actualmente a los tópicos en la publicidad turística, considerada cada vez más como un destacado factor en el desarrollo de estrategias de marketing centradas en la promoción de destinos turísticos. El marketing de destinos no parece estar alejado de las transformaciones sociopolíticas o económicas que se van sucediendo, puesto que dichos cambios inciden en cierta medida en la configuración de las campañas turísticas.

Atendiendo a estudios realizados por el Instituto de Turismo de España (TURESPAÑA), se constata que este país se posiciona, de forma significativa, como destino turístico en base a su componente emocional (Herce, 2007: 84-85). Posteriormente se han venido tratando estos valores culturales y otros de tipo artístico, apareciendo estos valores combinados con los consabidos y exitosos conceptos de sol y playa. Andalucía redunda igualmente en ellos. Realmente lo viene haciendo desde que inició su andadura en materia de turismo de forma independiente, al adquirir esta competencia cuando se alcanzó la autonomía, completándose el mapa autonómico español (Garrido, 2005: 78). Así, se aprecia que el marketing de destinos puede ser entendido desde dos posturas: una, la satisfacción de las necesidades del consumidor o turista por parte de una determinada región y dos, la adquisición de una posición competitiva, además del incremento cualitativo (Elizagarate, 2008: 51).

Al mismo tiempo, el concepto de competitividad viene ligado al uso de las nuevas tecnologías en estos días, convirtiéndose internet en un lugar de encuentro para muchas personas que buscan informarse, entretenerse o generar diversos contenidos. La red, por tanto, puede ser un conjunto de diversas audiencias a las que las empresas deben contemplar dirigirse, adaptando sus estrategias publicitarias y de marketing. 
Por todo ello, es necesario indicar que este estudio revisará igualmente el desarrollo de estas actividades promocionales en los medios digitales, ya que la red ayuda a conocer, y tal vez mejor, a los clientes potenciales gracias a la interactividad que posibilitan dichos medios digitales.

En pleno siglo XXI, debido al desarrollo de la globalización y a la situación de competencia que viven regiones turísticas cuyas fronteras ya no vienen marcadas por una línea (Losada Díaz y Correyero Ruiz, 2007: 215), igual es el momento adecuado para empezar a innovar.

\section{Aplicación de la tópica y la mercadotecnia a la publicidad turística}

Se denominan lugares comunes a aquellos contenidos generalmente conocidos y culturalmente compartidos por una serie de personas - emisores y receptores - en un mismo momento y en una misma sociedad. Por ello, este tipo de conocimientos ${ }^{1}$, fácilmente comprendidos por la mayoría, son usados asiduamente en el ámbito de la publicidad, en este caso turística. La argumentación retórica tiende a generar una especie de saber colectivo socialmente arraigado y actualmente alejado de simples ornamentaciones estéticas. Es más, dichos conocimientos están disponibles para ser usados en la creación de mensajes orientados al consumo y la comunicación. De este modo, el análisis de las diferentes isotopías a lo largo del presente discurso ayuda, en cierta forma, a descifrar todo un universo de significados implícitos, un universo semántico.

Para entender porqué se emplea esta argumentación retórica en labores publicitarias, se acude a conocidas concepciones aristotélicas que aclaran que hacer alusión a lugares comunes es hacer alusión a "una conciencia plural de razonamientos oratorios" (Berrio, 1983: 30) a la que poder apelar en caso de necesidad, porque como afirma Perelman y Olbrechts-Tyteca, una buena argumentación conseguirá provocar la adhesión del publico desencadenando a su vez una cierta predisposición en ellos (1989: 91).

Al respecto, el concepto citado como isotopía alude a rasgos semánticos contextuales y recurrentes en el discurso, reiterados a los largo del mismo, lo cuales proporcionan claves de lectura para configurar el universo temático y axiológico de la publicidad. Sánchez Corral (1997: 248-249) define este concepto desde un punto de vista semántico, redundando en la idea de la construcción de mensajes mediante el uso de "claves de lectura" o aspectos necesarios para la lectura posterior del mensaje.

Pero no solo comercialmente, sino que también cultural y socialmente se puede acudir a la tópica, ya que haciendo un análisis profundo de los diferentes mensajes publicitarios, descubrimos en ellos diversos reflejos culturales y populares propios de la sociedad y de la época en la que hayan sido creados. Un ejemplo cercano serían las campañas internacionales

\footnotetext{
${ }^{1}$ Los lugares, caracterizados por su generalidad, forman parte de un gran "arsenal", cuyo uso finalmente resulta imprescindible si se quiere persuadir a una auditorio concreto (Perelman y Olbrechts-Tyteca, 1989: 145-146).
} 
de publicidad española donde se muestra el típico carácter pasional asociado. Los españoles parecen destacar por su calidez, su profunda emoción y su extravagancia, es decir, por aspectos expresivos de la vida (Herce, 2007: 86). En este caso, se intuyen claves de lectura conformadas como estereotipos y destinadas a ser entendidas tanto por españoles como por públicos extranjeros. De este modo pervive en España esa imagen romántica que se asocia a tópicos tan conocidos como el del sol, los toros o el flamenco.

Así, para seducir al consumidor, resulta ser potentemente eficaz la actividad publicitaria, necesitando complementarse además con un toque emocional. $Y$ dicho toque viene de la mano de determinados aspectos propios del pueblo, siendo esa pasión asumida internacionalmente y dando lugar a los llamados estereotipos. Como es evidente, no se puede entender la publicidad sin la retórica (Rey, 2004: 71), puesto que el mensaje, sea del tipo que sea, se encamina al consumo final usando para ello razonamientos persuasivos. Es más, como afirman Cobo Durán y Hernández de Santaolalla tras citar a Rey y Fernández (2000: 42-43), "existen tres importantes características que unen la retórica a la publicidad: ambas afectan al terreno de la persuasión, en ambas prevalecen los argumentos emocionales sobre los racionales y en ambas existe la necesidad de conocer el auditorio" (2009: 149). Pese a todo ello, la retórica ha sido mal entendida en nuestros días, ya que el engaño se asocia erróneamente a la actividad publicitaria, cuyo fin último es la persuasión (Adam y Bonhomme, 2000: 117).

En definitiva de lo que se trata es de buscar la adhesión de un público gracias al uso de la persuasión, que no la artimaña. Sugerir, atraer o cautivar mediante la construcción de imágenes es el fin de la publicidad turística, la cual para conseguir esa adhesión se sirve de ciertos valores reconocidos por el público. Y, al no temerse ninguna contradicción en ellos, esos valores universalmente y socialmente compartidos pasan a ser verdades que gozan de bastante consistencia (Perelman y Olbrechts-Tyteca, 1989: 99-100).

Avanzando un poco más en la estrategia publicitaria podría decirse, como comentan Truong y Simmons, que se está cambiando el modelo de comunicación -en el que tenía una importante presencia la publicidad-, que consistía en un emisor que se dirigía a varios destinatarios (one-to-many) y sin posibilidad de feedback inmediato, para pasar a otro modelo en el que esos destinatarios o consumidores han tomado el poder (non-linear communication) (2010: 239-240).

En el globalizado mundo digital actual se ha ido generalizando el uso de la tecnología con diversos fines. Muchas personas buscan información sobre productos, comentan sus creencias sobre algunos temas generando corrientes de opinión o recomiendan servicios. Por ello, sería significativamente estratégico crear campañas que animen a los consumidores a hacer uso de estos nuevos entornos.

Dentro de este contexto tecnológico, resulta ventajoso promocionar una determinada marca, como bien indican Losada Díaz y Correyero Ruiz, gracias a diversos aspectos: 
- los atributos que conforman la identidad de la marca, así como los productos y servicios que la ciudad ofrece - en este caso región - se pueden difundir y promocionar [...] 24 horas al día los 365 días del año [...].

- la organización del portal en distintos canales permite segmentar la oferta del producto-ciudad y generar una oferta estructurada en función de los "clientes internos", los residentes de la ciudad y como "clientes externos" los visitantes, los turistas, los inversores y las empresas.

- A través de la página web se pueden conocer también cuales son los intereses de los clientes potenciales y facilitarles, de forma cómoda y ordenada, respuesta [...] e información $[\ldots]$.

- Internet es además un medio más de promoción muy económico [...] (2007: 215).

De ahí que grandes compañías estén dándose cuenta de que hay que trabajar en el ámbito de estas nuevas redes sociales para así generar reacciones inesperadas o percepciones actuales de sus marcas y productos. Las redes sociales pueden ser contempladas, por ejemplo, como espacios en los que insertar nuevos formatos publicitarios, generando así óptimas estrategias de marketing enfocadas en el aprovechamiento y uso de la red internet (Truong y Simmons, 2010: 242).

Aunque ésta es un área aún en crecimiento, la idea que se plantea es la de hacer un uso diferente y novedoso de este mundo digital, porque van surgiendo nuevas estrategias y nuevas posibilidades muy apropiadas para el desarrollo de marcas turísticas, como lo es la andaluza. En otras palabras, está siendo necesaria una integración entre nuevas tecnologías y objetivos de marketing.

Cierto es igualmente que, unido a estos contextos, destaca la importancia que se le concede a los sentimientos como plus del turismo, hasta tal punto que se han creado nuevas técnicas de marketing enfocadas hacia ello. Como indican Hudson y Brent Ritchie, gracias al uso de este tipo de tácticas se explotan conceptos como la conexión emocional entre países o áreas turísticas y sus posibles visitantes "felices", con una actitud favorable hacia la experiencia vivida: "destinations marketers are increasingly focusing in the tourist experience, and creating marketing messages based on these experiences that will appeal to the emotions of potential travellers" (2009: 217-218).

En definitiva, la publicidad turística, que generalmente busca transmitir mensajes emotivos y evocadores, poniendo de manifiesto la importancia argumentativa que adquieren ciertos valores compartidos, parece ser un elemento promocional en el que la aplicación de estas innovadoras técnicas de marketing puede ser sinónimo de éxito. Asimismo, esta nueva tendencia se ve reflejada en los actuales planes turísticos. En el plano andaluz, se están potenciando estrategias basadas en experiencias, de modo que una vivencia memorable en el destino se transforme en una motivación para viajar. Se aprecia así un mayor interés en desarrollar el eje centrado en el valor al cliente, dejando de lado la tradicional orientación hacia el producto. 


\section{Metodología y objetivos}

La intención de este trabajo es la de observar el tratamiento que reciben actualmente los estereotipos y tópicos en el ámbito de la publicidad turística andaluza, inmersos en esa visión global y competitiva en la que se hallan los destinos turísticos. Igualmente, se incluye en este análisis una breve descripción de la actual herramienta, objeto igualmente de este estudio, que facilita la difusión de la campaña turística en la red.

Para alcanzar estos objetivos, en este estudio se lleva a cabo un análisis de contenidos en el que se contempla la realización de una interpretación de carácter retórico y semiótico de la actual campaña turística Andalucía te quiere. A través de los diferentes elementos que la componen - spots, gráficos y cuñas de radio - se analizarán cuatro isotopías ${ }^{2}$, extraídas de una amplia clasificación realizada por Sánchez Corral, que tienen una aplicación directa en este planteamiento. La isotopía de la personalidad es entendida como autenticidad a nivel semántico, pero a la vez es una sobrevaloración del estímulo contenido en el discurso publicitario (nivel conceptual). Seguidamente, la cultura se usa como mecanismo de refuerzo persuasivo que busca proporcionar prestigio (isotopía de carácter figurativo). Las isotopías de seducción y placer buscan conmover al receptor, pues es bien sabido que la publicidad condensa la promesa del goce en su discurso. Y finalmente el cuarto tópico, el espacio, se muestra para apelar a diferentes motivaciones como puede ser el desplazamiento en busca de satisfacción o la creación de espacios idílicos, utópicos (1997: 251-298).

La investigación se centra en el análisis del material promocional creado para esta campaña y difundido por la empresa publica Turismo Andaluz S.A. mediante diversos medios de comunicación. Dicho material gráfico puede consultarse en la web de la agencia BBDO, al ser ésta la empresa que lo desarrolló y la que ideó la configuración actual de la marca Andalucía ${ }^{3}$.

Indudablemente, se valoran tópicos propiamente andaluces, pues como indica González Galiana (1999: 102), los estereotipos pasan a ser parte de la identidad de un grupo debido a su constante uso. Son, por tanto, signos sociales fácilmente reconocibles y, por ello, considerados auténticas "claves de lectura". De la mano del análisis semiótico se intenta descifrar ese mensaje connotativo contenido en esta campaña. Además, la mezcla de diversos códigos visuales y escritos empleados en la publicidad configuran unas determinadas narrativas que son interpretadas gracias a este tipo de análisis, según indica Javier Hernández (2008: 45). Así, con el análisis de contenidos se identifican ciertos tópicos empleados en estos elementos promocionales, a la vez que informaciones relevantes contenidas en la web. Y la interpretación semiótica ayuda, como complemento, a determinar la significación implícita de estos mensajes.

\footnotetext{
${ }^{2}$ Figuras retóricas que ayudan a ver en el análisis de contenidos el uso de la retórica.

${ }^{3}$ Con la que se pretende mostrar la expresión de todos valores de la comunidad y su extensa oferta turística mediante la amplia gama de colores de su logotipo.
} 
Por otra parte, la industria del turismo no es más que una forma de producir espacios (Díaz Pérez, 2006: 260). Por lo que en la comunicación turística se intentan representar lugares, generando una especie de fusión o conexión entre viajero y destino. Así, en el desarrollo de este análisis se hace necesaria la mención de las teorías sobre Marketing Experiencial. Gracias a éstas, se generan nuevas campañas publicitarias que inciden más en el aspecto psicológico y emotivo, dejando de estar únicamente centrado en el producto, para estarlo en mayor medida en el turista (Hudson y Brent Ritchie, 2009: 217-218).

En segundo lugar, mediante la observación y la interpretación de los contenidos del portal www.andalucia.org, se intenta conocer la difusión de dicha campaña en los actuales contextos digitales, a la misma vez que completar este estudio. Hay que destacar la creciente importancia que ha cobrado el mundo virtual, lo que ha provocado una intensa adaptación de las empresas hacia él, evidenciando nuevas concepciones como la interactividad, la generación de contenidos por parte de los internautas o la posible intrusividad de la publicidad digital, como sugieren Truong y Simmons (2010).

A través de este site se espera conseguir información y acceso a servicios que hagan de esta herramienta un buen elemento promocional en internet, a la vez que se ve favorecida positivamente la imagen andaluza y su colorida marca turística.

\section{Andalucía te quiere: estereotipos, convergencia digital e interculturalidad}

La campaña denominada Andalucía te quiere (2008/09) está conformada por bellos paisajes y compuesta por un principal componente audiovisual, dividido en varios spots con temáticas turísticas diferenciadas: sol y playa, escapadas de fin de semana, golf o turismo de reuniones, entre otras; por un componente gráfico, igualmente fragmentado temáticamente y plasmado en bellas postales, y finalmente, por un componente de refuerzo radiofónico.

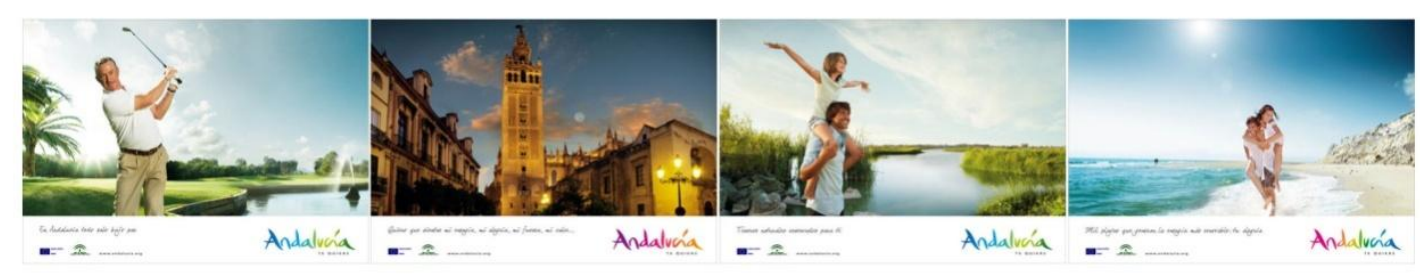

Figura 1. Varias de las postales que integran esta campaña.

Como se puede observar, a lo largo de esta campaña se evidencia el uso de ciertas isotopías anteriormente citadas. En un primer visionado, destaca esa llamada directa que hace la propia Andalucía al espectador o visitante, haciendo uso en este caso del tópico de la personalidad. Este discurso publicitario se caracteriza por ese primordial acento emotivo, donde Andalucía con tono dulce y cálido "quiere que sientas su energía, su alegría, su fuerza, su calor..." y quiere que seas tú quien sienta esa experiencia única, porque Andalucía te quiere a ti. La comunidad posee una serie de valores concretos para poder actuar sobre el 
turista, dirigiéndose directamente a él, de forma que la región andaluza aparece como un sujeto o emisor competente en materia turística (Ruiz Collantes, 2009: 274-275).

Aunque si se atiende a las consideraciones de la marca turística Andalucía como autor de esta comunicación, entonces es el consumidor el que adopta el papel de crítico llenando de sentido a la propia marca (Sasser, 2008: 184). Toda esta idea de unión, de conexión entre empresa y público, en definitiva, enlaza con el segundo tema planteado relativo a la difusión de estos contenidos turísticos en la red y al tratamiento de la interactividad, que será abordado más adelante.

La comunidad andaluza, en este caso hecha persona, transmite además otro tipo de emociones que completan esta inolvidable experiencia. Así, la alegría, la calidez o la paz se identifican con las diferentes tonalidades empleadas a lo largo de toda la campaña ${ }^{4}$ a través de una iluminación suave en imágenes playeras o de una más brillante en monumentos o paisajes. Asimismo, la marca turística Andalucía se acomoda respecto a las tonalidades de las imágenes, gracias a la amplia gama de colores que irradia el nuevo logotipo. Dicha marca se redefinió como "un crisol de colores", simbolizando y englobando así todas las ventajas competitivas del destino Andalucía (Garrido Lora y Muñiz Velázquez, 2010: 72).

Por otra parte, es indicativa la neutralidad que se aprecia en los rasgos físicos de los principales personajes, obviando así la típica sensualidad racial tan asociada a la personalidad andaluza, pero captando a la misma vez ese concepto tan intercultural y global que caracteriza a las sociedades actuales. Realmente no sólo se usan ya estereotipos de mujeres morenas con vestimenta típica, sino que se intenta transmitir una idea menos individualizada o centrada en el "nosotros" andaluz para centrarse en un "vosotros" más general, más global.

En este punto parece importante hacer un inciso para concluir que, según Rodrigo Alsina y Estrada Alsina, la interculturalidad es entendida como contacto entre diferentes culturas, pero llegando a producir hibridaciones o mestizajes, no una simple coexistencia (2007: 39).

Respecto a la cultura, entendida como clave, indicar que aparece en esta campaña para dotar a la comunidad andaluza de esa valoración positiva, frecuentemente asociada a lugares o puntos de encuentro de diferentes saberes. Culturalmente se aprecia la inexistencia del estereotipo andaluz de sombreros de ala ancha, salvo en el corte audiovisual genérico, donde sí se visualiza a una joven bailando ataviada con un "mantón" color crema. Tal ausencia podría entenderse como un tímido guiño hacia una mentalidad menos tradicional, pero nunca como una negación de costumbres propias.

El tópico de la seducción se evidencia principalmente en la conexión emocional que surge entre comunidad y potencial visitante, ofreciendo múltiples viajes a través del tiempo para

\footnotetext{
${ }^{4}$ Cobo-Durán y Hernández-Santaolalla señalan en su estudio que el valor que más se repite en las campañas andaluzas es el de lo exclusivo, haciendo que la región andaluza se muestre como destino único e integrado (2010: 133-134).
} 
conocer culturas, enumerando diferentes paisajes naturales relajantes o un inmejorable clima. De esta forma, el concepto seducción concentra diversos sentimientos, los cuales tratan de despertar en el turista el interés por viajar, apelando directamente a él. Esta campaña tiende a subrayar esa comunicación emocional dirigida hacia el turista, quedando ésta enmarcada en las diferentes imágenes correspondientes a los segmentos turísticos andaluces.

Finalmente, se podría decir que el tópico del espacio es el gran escenario en el que se enmarca esta campaña, de modo que éste es un importante recurso argumental y un destacado valor que representa lo andaluz: una constante natural ligada continuamente a la región (Cobo-Durán y Hernánez-Santaolalla, 2010: 129), además de ser la base en la estructura audiovisual de la misma. Así pues, esta campaña argumenta emotivamente a favor de la región gracias al uso de tópicos positivos insinuando un giro hacia la globalidad, a la vez que se van dejando atrás otros recursos, algo ya arcaicos, relativos a esa Andalucía romántica de peinetas y lunares.

Ante la demanda creciente del turismo de naturaleza, Andalucía ha decidido proyectar una imagen diversificada, que no olvida su destacada historia o sus tradiciones culturales, pero que si se completa con bellas imágenes de los espacio naturales andaluces. De este modo, Andalucía trata de incorporar a su oferta turística las transformaciones sociales que se van produciendo. Al atractivo de las tradiciones o la gastronomía se suma el interés por la sostenibilidad o por el deporte al aire libre. Lo que si es cierto es que, en una jerarquía de valores, el espacio ocuparía un lugar destacado, por ser el gran referente en esta campaña, es decir, su amplio marco.

Aparte de toda esta argumentación especial, y debido a la creciente competitividad que se está dando en el sector turístico, ha de desarrollarse una identidad que singularice al destino, como bien se puede apreciar en el desarrollo de esta acción promocional. Gracias al marketing experiencial, las campañas publicitarias se centran más en explotar las propias experiencias que viven los turistas, adoptando una nueva orientación que contrasta con la visión tradicional del marketing.

Por otra parte, el acercamiento hacia los potenciales turistas, o más bien el acercamiento que la propia marca turística andaluza hace, debe ser concordante con los nuevos contextos digitales. Según Simmons, extraído de Truong y Simmons (2010: 243), "they need to pull consumers into brand narratives that appeal to them within their online social networks, or within developed brand communities".

El propio Simmons vuelve a incidir en el hecho de que la participación del consumidor en el desarrollo de productos o servicios - interactividad - y la exposición de sus experiencias respecto a ellos resulta ser muy significativa para las empresas, además de aportar valiosa información de cara a la satisfacción posterior de las necesidades y deseos de esta nueva comunidad tan interactiva: 
Essentially, the internet allows empowered online postmodern consumers to interact in a meaningful way with companies (see Auger, 2005; Ibeh et al., 2005; Marcolin et al., 2005), developing a rapport which creates a relationship that allows these consumers to have a say in the online creation of product and services experiences, which are tailored to their individualized needs (see Jiang, 2002; Grenci and Watts, 2007, for expositions on oline consumer customisation) (2008: 303).

En relación a esta campaña, el interés por las nuevas tecnologías se ve materializado en la creación de portales de amplio contenido turístico. De este modo, ya se intuye la importancia que adquiere internet como herramienta integrante de las actuales estrategias publicitarias.

El portal turístico www.andalucia.org ${ }^{5}$ nace con la vocación de comunidad turística virtual y, como no, con la intención de servir de instrumento promocional. Así, entre las razones que originan la creación del mismo se intuye el deseo de ser un punto de encuentro donde poder informarse sobre todas las posibilidades que ofrece la región andaluza, es decir, servir de eje vertebrador en torno al cual poder construir la presencia de Andalucía en la red. Y para cumplir dicha misión, Garrido Lora y Muñiz Velázquez indican que la web andaluza cumple con varios objetivos. En primer lugar la web dispone de información de calidad para los usuarios, en segundo lugar se transmiten todas las ventajas competitivas de la región y, finalmente, en tercer lugar se añaden diferentes servicios complementarios que ayudan al potencial turista a configurar su anhelado viaje (2010: 78-79).

El principal corte audiovisual ${ }^{6}$, bien centrado y presente en ambas opciones de la web viajero y profesional -, muestra diversas imágenes pertenecientes a la propia campaña e incide en que Andalucía es además "un excepcional escaparate para todo lo relacionado con el turismo de Andalucía". En general, la web se divide visualmente en varios bloques de contenidos, distribuidos en tres franjas horizontales y englobando diversa información promocional estructurada en varias secciones. La parte superior facilita la navegación al usuario mediante un sencillo menú horizontal con 5 botones básicos: descríbenos, donde alojarte, que hacer, temporadas y red social.

Ya se sabe, que las redes sociales ${ }^{7}$ se han convertido en un importante lugar de encuentro, por lo que formar parte de ellas realmente significa convertirse en un destino atractivo, que posibilita un mayor conocimiento e interacción con los potenciales turistas. La web 2.0 fomenta esas diversas comunidades virtuales que permiten una novedosa construcción social y de contenidos en internet (López-Rodríguez, 2010: 141). Véase que aparece de forma destacada en la parte derecha de la web la expresión "Síguenos en la red", de modo que puedes conectar directamente con los perfiles que se han creado en diversas redes sociales como facebook o twitter. Gracias a todos ellos, los múltiples internautas pueden interactuar y

\footnotetext{
${ }^{5}$ Esta web promocional está gestionada por la empresa pública para la gestión del turismo y del deporte andaluz y ha sido recientemente redefinida, como bien indica su copyright: 2011.

${ }^{6}$ Recordar que este video recoge, a lo largo de sus tres minutos de duración, todas las temáticas diferencias en la campaña: Sol y playa, naturaleza, deporte, tradición, ocio, cultura, gastronomía, salud y negocios. Dichas temáticas buscan alcanzar del mismo modo sus propios objetivos específicos.

7 Podrían definirse como webs en las que se constituyen grupos de personas que, o bien tienen una relación de amistad, o comparten intereses comunes, lo cual favorece la posibilidad de compartir información, fotografías o videos (2010: 145).
} 
generar contenidos, es decir, subir fotos, opinar o simplemente informarse, pero fundamentalmente estas personas están contribuyendo en la labor promocional de la región y están expandiendo igualmente esta visión de Andalucía en la red, tal vez desde cualquier punto del planeta y con un simple click.

Además, los consumidores virtuales aprecian el hecho de poseer amplios recursos informativos, pero también aprecian la disponibilidad de tener el control cuando están informándose. En estos contextos de las redes sociales, ellos se sienten libres para tomar decisiones o para buscar información relevante, en definitiva, para interactuar: "Within the context of control, a significant number of participants sought out - pulled - and utilized online social networks (MySpace and others), in order to source peer-relevant information about products/services" (Truong y Simmons, 2010: 247).

Inmediatamente debajo del citado video, se sitúa otra franja horizontal con información sobre los diferentes segmentos turísticos andaluces, como puede apreciarse en la figura 2. recogida en el anexo, los cuales aparecen fácilmente identificados gracias a las imágenes usadas para definirlos. El caso del segmento golf ejemplifica de forma clara esta idea, puesto que aparece la misma escena que se puede contemplar en la postal.

La siguiente franja parece estar destinada a contener información de actualidad, puesto que en el momento en el que se visitó esta web, mediados de mayo, la información que estaba disponible como actual era referente a los patios y la feria cordobesa. Pero además, el portal ofrece información sobre cuestiones climáticas o sobre cómo planificar tu viaje. Esta web te remite a diferentes buscadores temáticos para decidir dónde alojarte o qué espacios naturales ver, todo ello complementado con un detallado mapa de la región y con la posibilidad de descargar guías turísticas.

Realmente es llamativa la importancia que se le concede a la interactividad, a la participación de los consumidores en este portal, ya que en su menú superior inicial existe la posibilidad de hacerse "socio" y, por tanto, de formar parte de esta comunidad virtual e interrelacionarse con sus diversos miembros. Queda evidente que la intención de esta web es la de ofrecer la posibilidad de descubrir la región en profundidad, a la misma vez que se pueden hacer nuevos amigos.

Andalucía, de esto modo, posee su propia red social, con todas las ventajas que este tipo de espacios conlleva, la cual le sirve como herramienta planificadora de viajes y como conector de viajeros con organizaciones turísticas y con todos los recursos existentes en materia de turismo de la comunidad. Así, la expresión "Conéctate a la red social de Andalucía", supone la creación de un vinculo que va mas allá de la simple participación virtual, puesto que dicha unión te hace ser elemento activo de la comunidad andaluza.

Por otra parte, no se puede pasar por alto el hecho de que el turismo es uno de los principales motores económicos de la región. Razón por la cual, junto a todas estas ventajas 
centradas en los potenciales turistas o consumidores, destaca la opción que tienen los empresarios de este sector de beneficiarse de la participación en dicha comunidad virtual. De modo que quedan integrados en este proyecto promocional todos los principales actores implicados, como bien afirman Losada Díaz y Correyero Ruiz, bajo el mismo paraguas o marca turística y orientando sus esfuerzos hacia el desarrollo de Andalucía (2007: 220).

Esta sección profesional, a la cual se accede vía menú inicial, sigue el mismo diseño estructural informativo. Por supuesto, esta web puede consultarse tanto en español como en inglés, reforzando así ese carácter global, ese deseo de convertir a la comunidad andaluza en un destino diferenciado y único.

En resumen, tras revisar esta web, se deduce que toda esta acción promocional gira en torno a tres temáticas concretas. La principal temática es el turismo, evidentemente, pero a ésta se subordina la temática destino, es decir, la clasificación o valoración de todas las ventajas que el destino Andalucía posee y, la temática negocios, los cuales florecen con la diversificación del amplio sector turístico andaluz. Cada vez existen más posibilidades para los empresarios, en base a la gran segmentación producida y al peso que van cobrando en la región diversos segmentos desestacionalizadores, como puede ser el caso de los deportes náuticos y del golf o del turismo de salud, entre otros.

Igualmente es significativa la coordinación existente entre campaña y web, reforzando así el principal objetivo corporativo: la promoción de la comunidad andaluza y el ansiado posicionamiento como destino único. Por esta razón, tanto campaña como portal siguen una misma línea estética, ya que es importante que los diferentes elementos promocionales estén perfectamente alineados dentro de la estrategia global a seguir, marcada en última instancia por los planteamientos de las instituciones pertinentes en materia turística:

\begin{abstract}
When firms realize that their web site can be a significant medium for interacting with present and prospective consumers, they should also recognize that internet advertising is an integral element of corporate advertising strategy. A direct consequence of this acknowledgement should be the realization that a firm's collection of web sites must reflect corporate goals (Boudreau y Watson, 2006: 35).
\end{abstract}

\title{
5. Conclusiones
}

Después de todo lo expuesto anteriormente, la idea que resulta inicialmente más evidente en este análisis es la suavización dada a la "típica" definición de la región andaluza, años atrás más exaltada y pasional. Dicha suavización puede responder al deseo de modificación y modernización del estereotipo andaluz o bien al interés de situar a la comunidad en un entorno turístico más globalizado, en el que reina la interpenetración de culturas diversas. De modo que, citando a Rodrigo Alsina y Estrada Alsina, "la creación de sentido debe ser compartida por una colectividad suficiente - se añade también que sea igualmente amplia -, sino sería caer en el solipsismo" (2007: 38). No sería apropiado para la promoción exponer rasgos de un idealismo subjetivo que no admita más realidad que la percibida por uno 
mismo, así, estos nuevos tópicos expuestos en la campaña y relacionados con el territorio andaluz aparecen de forma amplia y fácilmente interpretables.

Andalucía debe ser competitiva no sólo en relación a su diverso producto turístico ofertado, sino que también debe tener una presencia competitiva en la red, la cual consigue gracias a su portal turístico y a la óptima combinación de información y servicios que ofrece (2010: 83).

Igualmente, gracias al acercamiento de las empresas a la red, ha sido posible el desarrollo de la comentada web turística, con la que se pretende no sólo mejorar la percepción de Andalucía como destino, sino que se pretende también situarla en un contexto más general para hacerla más visible y tener un fuerte presencia en todas las audiencias posibles. En este sentido, internet refuerza otras redes informales conocidas por todos, como el boca a boca, que siempre han apoyado indirectamente cualquier estrategia empresarial (Flores Vivar, 2009: 77).

Por lo tanto, parece tener sentido la idea de dejar atrás antiguos tópicos pasionales para dejar paso a otros neutros y globales, pero igualmente sugerentes y propios como lo es paisaje excepcional que enmarca esta campaña. A través de internet Andalucía difunde cualidades fundamentales que inciden directa y favorablemente en el fortalecimiento de la marca turística y lo hace mediante conceptos sencillos y neutros, asimilables cómodamente por todos. Sin duda, Andalucía quiere que todos disfruten de ella.

\section{REFERENCIAS BIBLIOGRÁFICAS}

AdAm, Jean-Michel; BonHomme, Marc (2000): La argumentación publicitaria. Retórica y elogio de la persuasión. Madrid, Cátedra.

BERRIO, Jordi (1983): Teoría social de la persuasión. Barcelona, Mitre.

BOUDREAU, Marie-Claude; WATSON, Richard T. (2006): "Internet advertising strategy alignment" en Internet Research, n० 16/1, pp. 23-37.

Cobo Durán, Sergio; Hernández de Santaolalla Aguilar, Víctor (2009): "El tópico de la cualidad y el individualismo en la publicidad: "El efecto J\&B"', en Questiones Publicitarias, no 14, pp. 145-157.

Cobo-Durán, Sergio; Hernández-SAntaolalla, Víctor (2010): "La identidad andaluza a través de su publicidad turística (2002-2008): 'La tuya', ahora 'te quiere'", en Perlado Lamo de Espinosa, M., y Jiménez Narros, C., Escenario actual de la investigación en Comunicación: objetivos, métodos y desafíos. Madrid, Edipo, pp. 126-139.

DÍAz PÉREZ, Flora Ma (2006): Política turística: La competitividad y sostenibilidad de los destinos. Valencia, Tirant lo Blanch. 
Elizagarate, Victoria (2008): Marketing de ciudades. Madrid, Ediciones Pirámide.

FLORES VIVAR, Jesús Miguel (2009): "Nuevos modelos de comunicación, perfiles y tendencias en las redes sociales", en Comunicar, no 33, pp. 73-81.

GARRIDO LORA, Manuel (2005): "La publicidad turística en Andalucía (2002-2005): Andalucía solo hay una. La tuya vs. Andalucía te quiere", en Questiones Publicitarias, no 10, pp. 77-97.

GarRido LorA, Manuel; MuñIz VelÁzquez, José Antonio (2010): "La web como reto para la promoción turística de Andalucía", en Guarinos, V., Andalucía en la red. La construcción de la imagen de lo andaluz en Internet. Sevilla, Fundación Centro de Estudios Andaluces, Consejería de la Presidencia, pp. 69-84.

GonzÁlez GalianA, Rafael (1999): "La construcción de estereotipos andaluces por los medios", en Comunicar, no 12, pp. 101-106.

GUARINOS GALÁN, Virginia (2009): "Questiones sobre la representación audiovisual de la nueva Andalucía. De la amistad al amor: Campaña Andalucía te quiere", en Questiones Publicitarias, nº 14, pp. 34-48.

Herce Pagliai, Silvia (2007): "España y sus estereotipos en la publicidad turística y comercial alemana", en El lenguaje publicitario en el turismo. Sevilla, Consejería de turismo, comercio y deporte, pp. 81-112.

HeRnÁndez Ramírez, Javier (2008): La imagen de Andalucía en el turismo. Sevilla, Fundación Centro de Estudios Andaluces, Consejería de la Presidencia.

Hudson, Simon; BRent Ritchie, J.R. (2009): "Branding Memorable Destination Experience. The case of Brand Canada.", en International Journal of Tourism Research, no 11, pp. 217-228.

LóPEZ-RODRÍGUEZ, Francisco Javier (2010): "Andalucía en la web 2.0", en Guarinos, V., Andalucía en la red. La construcción de la imagen de lo andaluz en Internet. Sevilla, Fundación Centro de Estudios Andaluces, Consejería de la Presidencia, pp. 141-154.

LOSADA díAZ, Juan Carlos; CORREYERO RUIZ, Beatriz (2007): "La marca ciudad a través de internet", en Baladrón Palacios, A. J., Martínez Pastor, E., y Pacheco Rueda, M., Publicidad y Ciudad. La comunicación publicitaria y lo urbano: perspectivas y aportaciones. Sevilla-Zamora, Comunicación social, ediciones y publicaciones, pp. 208-229.

PERELMAN, Ch.; OLBRECHTS-TYTECA, L. (1989): Tratado de la argumentación: la nueva retórica. Madrid, Gredos.

REY, Juan (2004): "Retórica y consumo: una propuesta metodológica", en Questiones Publicitarias, no 9, pp. 78-95. 
REY, Juan; FERNÁNDEZ GÓMEZ, Jorge David (2000): "Hacia una nueva retórica publicitaria", en Questiones Publicitarias, no 8, pp. 36-57.

RODRIGO ALSINA, Miguel; ESTRAdA ALSinA, Anna (2007): "La ciudad intercultural", en Baladrón Palacios, A. J., Martínez Pastor, E., y Pacheco Rueda, M., Publicidad y Ciudad. La comunicación publicitaria y lo urbano: perspectivas y aportaciones. Sevilla-Zamora, Comunicación social, ediciones y publicaciones, pp. 32-44.

RUIZ Collantes, F. Xavier (2009): "El Estado es el producto. Publicidad institucional, rutinas discursivas e ideología de Estado.", en Questiones Publicitarias, monográfico no 3, pp. 268-293.

SÁNCHEZ CORRAL, Luis (1997): Semiótica de la publicidad. Narración y discurso. Madrid, Síntesis.

SASSER, Sheila L. (2008): "Creating passion to engage versus enrage consumer cocreators with agency co-conspirators: unleashing creativity", en Journal of Consumer Marketing, no 25/3, pp. 183-186.

TRUONG, Yann; SIMMONS, Geoff (2010): "Perceived intrusiveness in digital advertising: strategic marketing implications", en Journal of Strategic Marketing, no 18/3, pp. 239-256.

[Recibido: 23 de mayo de 2011. Aceptado (con solicitud de cambios): 25 de mayo de 2012. Recepción del artículo corregido: 4 de junio de 2012]. 


\section{ANEXO}

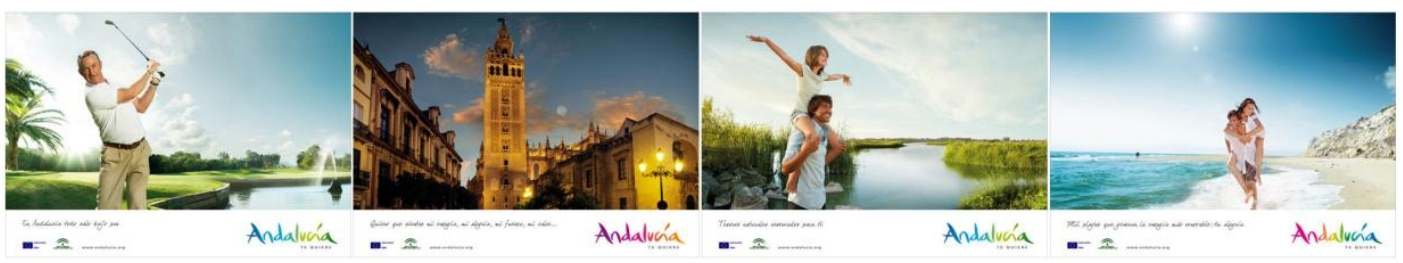

Figura 1. Varias de las postales que integran esta campaña.

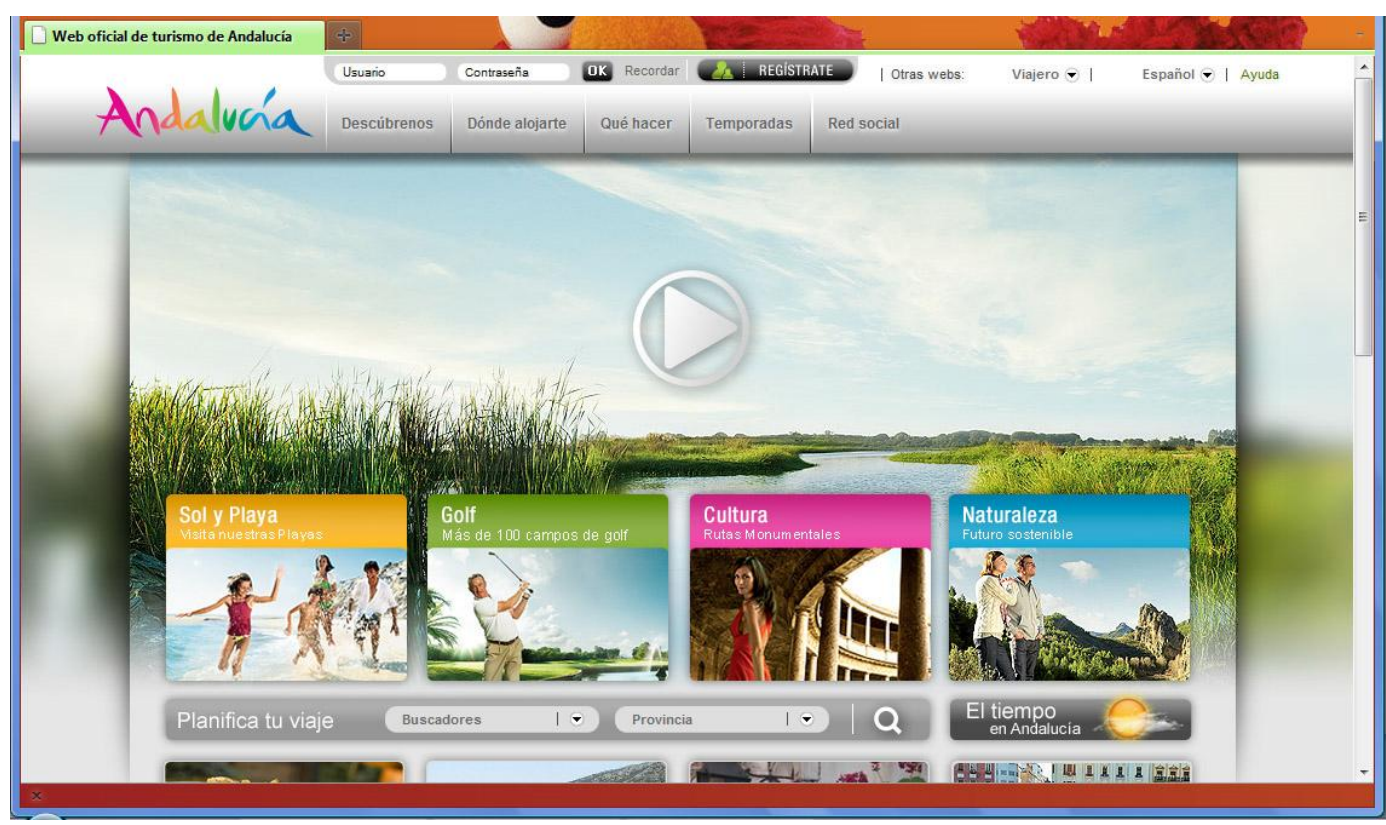




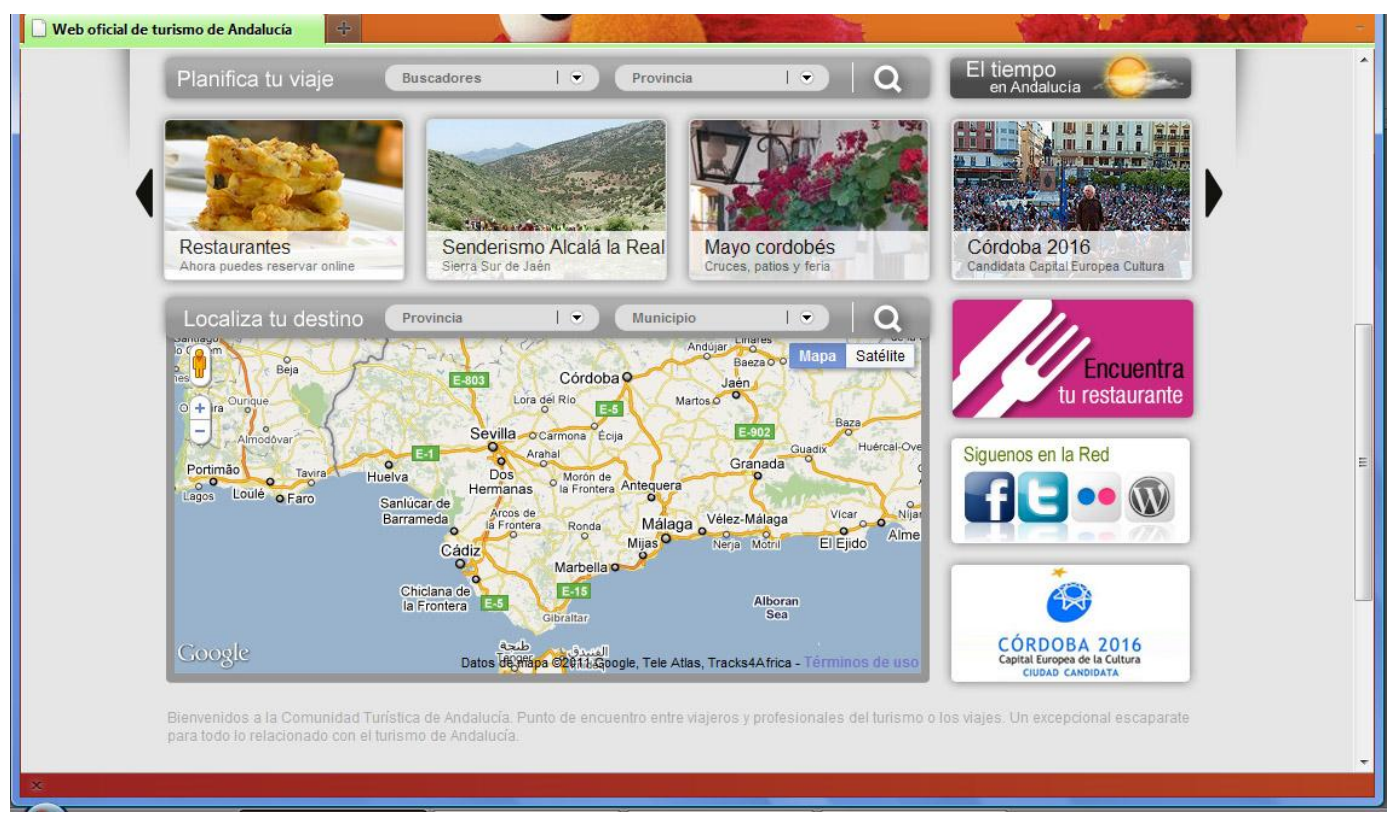

Figura 2. Portal turístico www.andalucia.org. 